Urologe

https://doi.org/10.1007/s00120-021-01641-2

() Der/die Autor(en) 2021

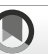

Check for
updates

\section{Erratum zu: Symptomatische Hodenmetastase eines azinären Adenokarzinoms der Prostata}

\author{
L. Kollitsch ${ }^{1}$ C. Hamann ${ }^{1}$ - S. Knüpfer ${ }^{1}$ - D. Meyer ${ }^{1} \cdot$ P. Kneissl ${ }^{1} \cdot$ E. Jüttner ${ }^{2}$ - D. Osmonov ${ }^{1}$ \\ ${ }^{1}$ Klinik für Urologie und Kinderurologie, Universitätsklinikum Schleswig-Holstein-Campus Kiel, Kiel, \\ Deutschland \\ ${ }^{2}$ Institut für Pathologie, Universitätsklinikum Schleswig-Holstein-Campus Kiel, Kiel, Deutschland
}

\section{Erratum zu: \\ Urologe 2020 \\ https://doi.org/10.1007/s00120-020- \\ 01194-w}

Der Artikel „Symptomatische Hodenmetastase eines azinären Adenokarzinoms der Prostata" von L. Kollitsch, C. Hamann, S. Knüpfer, D. Meyer, P. Kneissl, E. Jüttner und D. Osmonov wurde ursprünglich Online First ohne „Open Access" auf der Internetplattform des Verlags publiziert. Nach der Veröffentlichung in Bd. 59 Heft 9 pp. 1092-1094 hatten sich die Autoren für eine „Open Access"-Veröffentlichung entschieden. Das Urheberrecht des Artikels wurde deshalb in @ Der/die Autor(en) 2020 geändert. Dieser Artikel ist jetzt unter der Creative Commons Namensnennung 4.0 International Lizenz veröffentlicht, welche die Nutzung, Vervielfältigung, Bearbeitung, Verbreitung und Wiedergabe in jeglichem Medium und Format erlaubt, sofern Sie den/die ursprünglichen Autor(en) und die Quelle ordnungsgemäß nennen, einen Link zur Creative Commons Lizenz beifügen und angeben, ob Änderungen vorgenommen wurden.

Die in diesem Artikel enthaltenen Bilder und sonstiges Drittmaterial unterliegen ebenfalls der genannten Creative Commons Lizenz, sofern sich aus der Abbildungslegende nichts anderes ergibt. Sofern das betreffende Material nicht unter der genannten Creative Commons Lizenz steht und die betreffende Handlung nicht nach gesetzlichen Vorschriften erlaubt ist, ist für die oben aufgeführten Weiterverwendungen des Materials die
Einwilligung des jeweiligen Rechteinhabers einzuholen.

Weitere Details zur Lizenz entnehmen Sie bitte der Lizenzinformation auf http://creativecommons.org/licenses/by/ 4.0/deed.de.

\section{Korrespondenzadresse}

\section{Kollitsch}

Klinik für Urologie und Kinderurologie, Universitätsklinikum Schleswig-HolsteinCampus Kiel Kiel, Deutschland stu200603@mail.uni-kiel.de

Funding. Open Access funding enabled and organized by Projekt DEAL.

Open Access. Dieser Artikel wird unter der Creative Commons Namensnennung 4.0 International Lizenz veröffentlicht, welche die Nutzung, Vervielfältigung, Bearbeitung, Verbreitung und Wiedergabe in jeglichem Medium und Format erlaubt, sofern Sie den/die ursprünglichen Autor(en) und die Quelle ordnungsgemäß nennen, einen Link zur Creative Commons Lizenz beifügen und angeben, ob Änderungen vorgenommen wurden.

Die in diesem Artikel enthaltenen Bilder und sonstiges Drittmaterial unterliegen ebenfalls der genannten

Die Online-Version des Originalartikels ist unter https://doi.org/10.1007/s00120-020-01194-w zu finden.

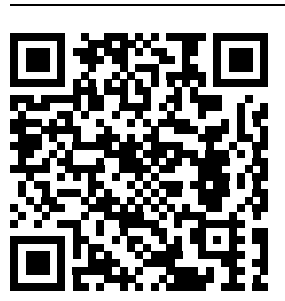

QR-Code scannen \& Beitrag online lesen 


\section{Erratum}

Creative Commons Lizenz, sofern sich aus der Abbildungslegende nichts anderes ergibt. Sofern das be-

treffende Material nicht unter der genannten Creative

Commons Lizenz steht und die betreffende Handlung nicht nach gesetzlichen Vorschriften erlaubt ist, ist für die oben aufgeführten Weiterverwendungen des Materials die Einwilligung des jeweiligen Rechteinhabers einzuholen.

Weitere Details zur Lizenz entnehmen Sie bitte der Lizenzinformation auf http://creativecommons.org/ licenses/by/4.0/deed.de. 